\title{
EDUCAÇÃO PARA A COMPETITIVIDADE OU PARA A CIDADANIA SOCIAL?
}

Fernanda A. da Fonseca Sobral

Professora do Departamento de Sociologia da Universidade de Brasília

\begin{abstract}
Resumo: O objetivo deste artigo é discutir a abordagem contemporânea dada à educação na sociedade brasileira, sobretudo às idéias de educação como promotora de competitividade e de cidadania social, mostrando, outrossim, como essas concepções de educação se refletem na política educacional brasileira da década de 90 e como estão relacionadas a certas transformações da sociedade brasileira, nas quais se incluem o processo de globalização e a consolidação da democracia.

Palavras-chave: educação no Brasil; cidadania; democracia.
\end{abstract}

$\mathrm{A}$ s formas pelas quais a educação vem sendo abordada na sociedade brasileira têm variado historicamente, evidenciando a idéia de Durkheim de que a educação é um processo de socialização (que integra os indivíduos no contexto social) e, por essa razão, varia segundo o tempo e o meio. Embora supondo que a educação não apenas integra o indivíduo ao meio social, mas também lhe proporciona uma maior capacidade de autonomia e, por isso mesmo, de interferência no meio social, é relevante mostrar que a educação sempre tem uma importância eminentemente social, ainda que essa questão assuma conotações diferentes através da história.

A intenção aqui é de discutir a abordagem contemporânea dada à educação na sociedade brasileira, sobretudo às idéias de educação como promotora de competitividade e de cidadania social, mostrando, outrossim, como essas concepções de educação refletem-se na política educacional brasileira da década de 90 e como estão relacionadas a certas transformações da sociedade brasileira, nas quais se incluem o processo de globalização e a consolidação da democracia.

Porém, antes da discussão sobre as idéias atuais sobre educação, será apresentada de forma resumida a relação entre educação e sociedade brasileira em diferentes momentos da história do país.

\section{A RELACÃO EDUCAÇÃO E SOCIEDADE ATRAVÉS DA HISTÓRIA ${ }^{1}$}

Nos anos 50 e até o início da década de 60, a educação é sobretudo considerada um instrumento de mobilidade social. Neste quadro, além das funções de socialização e de formação, a educação deveria dar "status" aos indivíduos.

A educação representava, para o indivíduo, a possibilidade de ascensão na hierarquia de prestígio que caracterizava a estrutura piramidal da sociedade e, para a sociedade, uma maior abertura do sistema de estratificação social.

Nesse período, o contexto mundial é caracterizado pela reestruturação social abalada pela Segunda Guerra Mundial, pelo fortalecimento do bloco socialista e pela configuração dos sistemas capitalistas e socialista em áreas definidas. Havia então uma preocupação com a legitimação da social-democracia, ameaçada pela ideologia fascista do passado e pelo socialismo soviético.

No Brasil, Florestan Fernandes (1972) caracteriza esse período pela passagem de uma ordem social estamental para uma ordem competitiva. Além disso, é um momento em que as idéias de democracia (mais populista do que liberal no Brasil) eram enfatizadas, e através delas pretendia-se diminuir o poder das oligarquias, fortificar a burguesia nascente e dar uma certa participação eleitoral às massas. 
Nessa sociedade mais aberta que emergia, mesmo a educação continuando a ter uma função decorativa de consolidar "status" sociais definidos por critério de origem socioeconômica, ela também passa a ser requerida como um instrumento de mobilidade social ascendente, sobretudo para as classes médias.

Também tem lugar a substituição de importações após a grande depressão mundial, quando ocorreu um rompimento com o modelo agroexportador. Daí resulta um estímulo considerável à industrialização de bens de consumo duráveis.

Nesse sentido, a educação tinha um papel importante no processo de legitimação pelo grau de abertura da sociedade. Uma sociedade em processo de industrialização e de democratização deveria mostrar um sistema de estratificação social mais fluído.

Diferente é o período posterior. Durante o governo autoritário, em vez de uma preocupação predominante dos estudos em mostrar alterações quanto a barreiras sociais menos rígidas, típica de uma ideologia democrática, a intenção era sobretudo mostrar a possibilidade de rendimentos oferecida pela educação, ou seja, evidenciar os seus aspectos econômicos, típica de uma ideologia desenvolvimentista.

Nos meados da década de 60 e nos anos 70 , há uma ênfase dos estudos econômicos da educação. A partir do trabalho de Schultz (1973), são utilizados conceitos como o de capital humano, para explicar o investimento em educação, o de produtividade, taxa de retorno, custos da educação e a concepção de educação enquanto mercadoria. Essa visão de educação repercute na sociedade em termos de crescimento econômico e nos indivíduos quanto à melhoria de renda, através de uma maior qualificação para o mercado de trabalho.

Nesse período, mundialmente, há a consolidação do sistema capitalista monopolista em contraposição ao sistema socialista. Também esse momento é marcado pelo crescimento econômico surpreendente da Alemanha e do Japão no pós-guerra, fenômeno impossível de ser explicado pela economia clássica a partir dos três fatores de produção, terra, capital e trabalho, exigindo um novo conceito explicativo, como o de "capital humano". Também a democracia liberal passa a ser substituída por Estados intervencionistas na esfera econômica.

No Brasil, esse período é caracterizado pela importância da intervenção do Estado na economia, visando a superação do subdesenvolvimento. Ocorreram uma industrialização progressiva e uma internacionalização da estrutura produtiva, aspectos já observados ao final da década de 50. O desenvolvimento era considerado enquanto modernização e, neste sentido, a inserção do país no mercado internacional era essencial.

Embora o modelo econômico de substituição de importações tenha se esgotado e o período 1963-67 tenha passado por baixas taxas de crescimento, a partir de 1968 começa uma nova fase de expansão que vai levar ao chamado "milagre econômico brasileiro". Neste quadro, delineia-se uma política educacional preocupada sobretudo com a rentabilidade dos investimentos educacionais.

Frutos dessa política são a Reforma Universitária de 1968 e a Lei de Profissionalização do Ensino Médio de 1971, que se baseavam na constatação da deficiência de mão-de-obra qualificada necessária ao desenvolvimento econômico do país e da discrepância entre a preparação oferecida pelo sistema educacional e as necessidades da estrutura de emprego.

Porém, é importante destacar a política econômica e desenvolvimentista contida na Reforma Universitária, ou seja, a idéia de que a universidade revelava-se inadequada para atender às necessidades do processo de desenvolvimento e modernização que estava ocorrendo, exigindo, portanto, a racionalização das atividades universitárias (criação do departamento, do sistema de créditos, do ciclo básico), a fim de lhes conferir maior eficiência e produtividade, aspecto peculiar à análise econômica da educação.

Assim, a criação da pós-graduação no Brasil e o início das atividades de pesquisa na universidade são o resultado de uma política estatal que visava a modernização do ensino superior dentro de um projeto de desenvolvimento. Essa era então a função social da universidade: qualificar recursos humanos e produzir conhecimento científico e tecnológico, no sentido de permitir a expansão industrial brasileira.

Assim, há uma mudança na forma de legitimação possibilitada pela educação. Se anteriormente a mobilidade social resultante do acesso à educação expressava uma sociedade mais aberta e democrática, nas décadas de 60 e 70 a legitimação tem base mais econômica, ou seja, o importante é o papel da educação no desenvolvimento. O que importa nesse período é o crescimento econômico e menos a fluidez da sociedade.

No final da década de 70, a abertura política começa ao mesmo tempo em que se assiste o final do milagre econômico brasileiro. Neste período, a educação passa a ser considerada politicamente, em que se coloca sobretudo o 
seu papel na construção da cidadania. Trata-se de um momento de crise de legitimação do Estado, em que os movimentos sociais tiveram um papel importante no sentido de retorno à democratização do país. Há um aprofundamento da discussão sobre o papel das políticas sociais, das políticas públicas na construção da democracia e cidadania, ao lado dos avanços na democratização do país que culminaram com a instituição da anistia, a criação de novos partidos políticos e a realização das primeiras eleições diretas para governadores.

Também no contexto mundial foi o auge do desenvolvimento do Estado de Bem-Estar Social, sendo que a democratização passa também a ser muito enfatizada, devido à proeminência da queda do Muro de Berlim, que simbolizava o fim do socialismo.

Neste sentido, a democratização do acesso e da gestão da educação era fundamental, tornando então crucial a questão do ensino público em termos da gratuidade e da garantia de recursos públicos e das eleições para os cargos diretivos das instituições educacionais. Quanto à universidade, além do seu papel na construção da cidadania para o qual eram necessárias a ampliação do seu acesso, a democratização dos seus instrumentos de gestão e a sua autonomia, também lhe era requerida a função de contribuir para a autonomia do país.

Esta preocupação deve-se ao fato de um novo conceito de desenvolvimento colocado nesse período: apesar de o processo de internacionalização continuar em vigor, a aspiração de autonomia nacional se faz dominante através da necessidade de geração de conhecimento científico e tecnológico, tendo em vista a superação da dependência em relação aos países centrais (estas idéias vão dominar o período da Constituinte). Neste projeto de autonomia, a competência científica e a consolidação da pósgraduação na universidade eram muito importantes, pois o ciclo completo de produção do conhecimento não podia ser dominado sem a pesquisa básica, geralmente realizada na universidade, embora a competência tecnológica e o papel da empresa nacional não tenham sido preteridos neste período.

Assim, a educação traria para o indivíduo a sua cidadania no sentido tanto do acesso ao ensino público e gratuito como da sua participação nas diferentes esferas do poder, o que significaria, para a sociedade, uma maior democratização e também uma maior autonomia (através da capacitação científica da universidade), ou seja, a legitimação inspirada pela educação era mais de caráter político.
Já na década de 90, a educação é considerada, sobretudo, promotora de competitividade. Essa educação que possibilita a competitividade dá ao indivíduo a condição de empregabilidade e traz para a sociedade a modernidade associada ao desenvolvimento sustentável.

O novo contexto mundial é marcado pela globalização e pela menor intervenção do estado na economia, o que estimula ainda mais a competição entre os países e entre as empresas. Além disso, começa a se instalar um novo paradigma produtivo, cuja base técnica é eletroeletrônica, própria do sistema industrial de automação microeletrônica e que está ancorado sobretudo no conhecimento e na educação.

Enquanto o fordismo caracterizava-se pela rigidez e simplificação do trabalho, pelo parcelamento de tarefas e pela especialização do conhecimento, o toyotismo (originado no Japão), paradigma vinculado à base eletroeletrônica, tem como características a maleabilidade, a conjugação de tarefas e o conhecimento mais holístico com maior potencial de criatividade. Essas novas tendências levam a pensar o conhecimento pela interdisciplinariedade, intercambialidade e experimentação ${ }^{2}$ (Peliano, 1998). Nesse contexto, educação e conhecimento estão muito associados a desenvolvimento científico e tecnológico que, por sua vez, levam à competitividade.

Diante do processo de globalização, da maior abertura do nosso país ao mercado internacional e da tentativa de entrar no novo paradigma produtivo, a formação de recursos humanos torna-se importante para aumentar a nossa competitividade, seja pela formação de pesquisadores altamente qualificados pelas universidades e pelo sistema de pós-graduação e que são responsáveis pela produção científica de ponta e pela produção de novas tecnologias, seja pela modernização tecnológica das empresas que dependem da pesquisa científica de ponta e também da educação básica e profissional de sua mão-de-obra.

Dessa forma, os indivíduos tornam-se mais competitivos no mercado, ou seja, com maior grau de empregabilidade, assim como as empresas ficam mais competitivas no mercado internacional, contribuindo para o desenvolvimento de nossa sociedade. Percebe-se nesse contexto uma legitimação de caráter mais econômico, possibilitada pela educação.

Um dos princípios atuais do "Consenso de Washington" é de que a educação é base para o desenvolvimento, idéia já vigente na década de 70 com a economia da educação, que afirmava serem os investimentos em educação muito importantes para o crescimento econômico do país. A no- 
vidade da década de 90 é que não é apenas a educação. Educação, ciência e tecnologia estão sendo consideradas um tripé para o desenvolvimento.

O retorno da racionalidade econômica, característica da abordagem econômica da educação pela teoria do capital humano (Schultz, 1973), é explicado, nos países desenvolvidos, pela crise do welfare state e, na América Latina, pela crise do Estado desenvolvimentista (Benakouche, 1999). Enquanto a crise nos primeiros é verificada pelo fato de que a intervenção no Estado na área social, para atender às crescentes demandas sociais, se traduz num déficit fiscal, a crise do Estado desenvolvimentista é explicada pela maciça intervenção do Estado na economia, tornando-se onipresente nas atividades de produção de bens e serviços, levando-a à ineficiência e ineficácia. "A idéia é de eliminar o Estado-Burocrático e Patrimonialista para colocar no lugar o Estado-Empresário" (Benakouche, 1999:34). "Persegue-se, portanto, a diminuição do tamanho do Estado, a redução de custos, o aumento da produtividade, o uso das técnicas de qualidade. Ora, esse encadeamento de conceitos tem um nome e um sobrenome: ele se chama economicidade para não dizer economia" (Benakouche, 1999:35).

Embora a racionalidade econômica permeie a idéia de educação para a competitividade na política educacional brasileira recente, não se pode ignorar, entretanto, uma concepção social da educação, no que se refere à ampliação das oportunidades educacionais para diminuir as desigualdades sociais, concretizando-se, dessa forma, uma sociedade mais justa. No período da redemocratização, a cidadania política foi muito reforçada, porém atualmente verifica-se que essa não foi suficiente para consolidar uma maior participação na sociedade, ou seja, uma maior cidadania social. Por essa razão, a educação passa a ser também considerada promotora de cidadania social.

As idéias de cidadania política e social têm suas origens no pensamento de Marshall (1979), quando o autor vincula o conceito de cidadania a partir do desenvolvimento dos direitos, iniciando com o aparecimento dos direitos civis, políticos e, finalmente, os sociais. Os direitos civis referem-se aos direitos necessários à liberdade individual, os direitos políticos compreendem a participação no exercício do poder e os direitos sociais, que surgem no século XIX, correspondem ao desenvolvimento das leis trabalhistas e à implantação da educação primária pública. São estes direitos que constituem a cidadania social, diferentemente da cidadania política mais carac- terística do período anterior e que se limitava sobretudo à participação no poder.

Ou seja, a educação é importante para o país enquanto condição de competitividade, no sentido de permitir a entrada no novo paradigma produtivo que é baseado, sobretudo, na dominação do conhecimento. Porém, a educação também é considerada relevante no que se refere ao seu papel de diminuição das desigualdades sociais, ou seja, como promotora de cidadania social. Dessa forma, o desenvolvimento é obtido através de uma maior competitividade dos indivíduos, das empresas e do país no mercado internacional, bem como através de uma maior participação social dos cidadãos. Isto é o que indicam as políticas mais recentes para a área educacional, que priorizam o ensino fundamental e procuram avaliar e reformar os ensinos médio e superior. "A nova LDB como um todo, em face das suas indefinições e dubiedades, ao que muitos denominam flexibilidade, permite que possa ser realizada uma educação comprometida tanto com o pressuposto de 'educação para a cidadania' como com o pressuposto da 'educação para a competitividade' - hoje, a perspectiva mais em voga, tanto na educação profissionalizante como na educação propedêutica" (Teixeira, 1999:97).

\section{CONCEPÇÕES DE EDUCAÇÃO NAS POLÍTICAS PARA OS ENSINOS FUNDAMENTAL E MÉDIO}

A idéia de educação para competitividade, associada ao desenvolvimento científico e tecnológico, e a idéia de educação para a cidadania social constituem consensos na agenda dos debates e formulação de políticas educacionais em âmbito internacional.

As citações apresentadas a seguir confirmam esta tendência: "a educação passa a ocupar, junto com as políticas de ciência e tecnologia, lugar central e articulado na ponta das macropolíticas do Estado, como fator importante para a qualificação dos recursos humanos requeridos pelo novo padrão de desenvolvimento, no qual a produtividade e a qualidade dos bens $\mathrm{e}$ produtos são decisivos para a competitividade internacional. Ainda que por si só a educação não assegure a justiça social, nem a erradicação da violência, o respeito ao meio ambiente, fim das discriminações sociais e outros objetivos humanistas que hoje se colocam para as sociedades, ela é, sem dúvida, parte indisponível do esforço para tornar as sociedades mais igualitárias, solidárias e integradas" (Mello, 1998: 43). 
No que se refere à melhoria da educação fundamental, considerada prioritária pelo atual governo, pode-se supor que ela está sendo pensada sobretudo dentro da perspectiva de promoção da cidadania social. Para isso foi criado o Fundef (Fundo de Manutenção de Desenvolvimento do Ensino Fundamental e de Valorização do Magistério) pela Emenda Constitucional no 14, de 12/10/96, que subvincula $60 \%$ dos $25 \%$ da receita de impostos constitucionalmente vinculados à educação. Trata-se de um fundo contábil que, além de transferir recursos para escolas públicas estaduais e municipais, propõe alterações na legislação vigente, redefinindo o papel da União, dos estados e dos municípios na oferta do ensino obrigatório e gratuito, estabelecendo vinculações de recursos para o ensino fundamental.

Este fundo, que teve início no Pará, em 1997, e nos demais estados, em 1998, apresenta os seguintes objetivos: promover a justiça social; uma política nacional de eqüidade; efetiva descentralização da gestão educacional do ensino fundamental, junto a estados e municípios; melhoria da qualidade e valorização do magistério público (MEC, 1999). O Fundef tem como meta, também, garantir o aumento da média salarial do magistério do ensino fundamental no país, a colocação de maior volume para os municípios e a garantia de uma redefinição de responsabilidades entre municípios, estados e Distrito Federal.

Os documentos governamentais reforçam, sobretudo, a importância da melhoria do ensino fundamental para a promoção da justiça social, uma vez que $14,7 \%$ da população de 15 anos ou mais ainda era analfabeta em 1996 (IBGE, 1996), embora os dados do MEC/Inep/Seec para esse mesmo ano já indiquem uma taxa de escolarização líquida de $95 \%$ para o ensino fundamental.

Assim, a educação fundamental é considerada o patamar inicial para a conquista da cidadania social, sabendo-se, entretanto, que ela só será de fato viabilizada com a universalização da educação básica. Ou seja, mesmo concordando com a priorização do ensino fundamental, essa decisão afetou o ensino médio, pois o Fundef vem romper com a concepção de educação básica conquistada pela LDB (que compreende a educação infantil, fundamental e média como um bloco de aprendizagem básica para toda a população), além de excluir os jovens e os adultos do âmbito dos seus recursos e de diminuir os recursos para a educação infantil e média (Teixeira, 1999).

No entanto, deve-se ressaltar também que a melhoria do ensino fundamental é crucial do ponto de vista do desenvolvimento científico e tecnológico do país e da competitividade. É o ensino fundamental que dá a formação básica para o futuro cientista, tecnólogo, técnico ou trabalhador, pois a introdução e a absorção de novas tecnologias características do novo paradigma produtivo exigem, além da formação específica, certos conhecimentos básicos e gerais, como pode-se notar na citação a seguir: "Surgem novos perfis de qualificação de mão-deobra. Inteligência e conhecimento parecem ser as variáveis-chave para a modernização e produtividade do processo de trabalho, como também a capacidade de solucionar problemas, liderar, tomar decisões e adaptar-se a novas situações. O modelo de adestramento profissional em tarefas ou etapas segmentadas do processo produtivo tende a ser substituído por outro, com grande ênfase na formação básica em Ciências, Linguagem e Matemáticas" (Mello, 1998:34).

As transformações no mundo produtivo e os novos perfis de trabalho que devem ser formados pelo sistema educacional apresentam-se tão evidentes que, na LDB, promulgada em 22 de dezembro de 1996, "inova-se o conceito de educação, introduzindo o componente trabalho como princípio educativo e como elemento que detém estreita relação com a educação geral e a conservação do conhecimento" (Teixeira, 1999:97).

Essa associação entre educação, trabalho e desenvolvimento tecnológico aparece mais enfaticamente na política para o ensino médio. Segundo dados da Sinopse/96 MEC/Inep/Seec, a taxa de escolarização na faixa etária de 15 a 19 anos é de apenas $34,4 \%$. No que se refere à distribuição de matrículas no ensino médio por dependência administrativa, há declínio no setor privado entre 1971 e 1996 (de 43,5\% para 19,8\%) e crescimento do setor público com predomínio do estadual (72,1\%), além de 58,8\% dos alunos estarem estudando no período noturno. Isto é, embora esteja ocorrendo um aumento das matrículas no ensino médio, esse fato não se deve, necessariamente, a uma maior qualidade do ensino fundamental que ainda apresenta altos índices de evasão e repetência, mas sim a "resultados de exames supletivos e a retornos de adultos que interromperam seus estudos há algum tempo" (Lobo, 1998:6).

Porém, um dos maiores problemas do ensino médio no Brasil e que se reflete nas suas políticas é o da sua identidade: oscila entre o ensino propedêutico, cujo objetivo é preparar o aluno para o ensino superior, e a formação profissional, que tende a ser vinculada às necessidades do mercado de trabalho.

Buscando superar os impasses provocados pela Lei $\mathrm{n}^{\mathrm{o}}$ 5.692/71, que procurou profissionalizar todo o ensino 
médio mas que, de fato, aprofundou a sua dualidade ou a sua ambigüidade, esvaziando tanto o ensino propedêutico quanto o profissionalizante, a LDB de 1996 visou preservar o caráter unitário da formação da pessoa, partindo da proposta de educação geral como eixo unificador, ficando a educação profissional condicionada à ampliação de sua duração. "O ensino médio, atendida a formação geral do educando, poderá prepará-lo para o exercício de profissões técnicas (art. $36 \S 2^{\circ}$ ), no próprio estabelecimento de ensino ou em cooperação com instituições especializadas. Os cursos médios terão equivalência legal e habilitação ao prosseguimento dos estudos" (art. $36 \S \S 3$ e 4) (Lobo, 1998).

Entre as finalidades básicas do ensino médio, está a preparação básica para o trabalho e para o exercício da cidadania, já refletindo as idéias de educação para a competitividade e de educação para a cidadania social. No que se refere à política para o ensino médio, há uma ênfase maior na sua vinculação ao mundo do trabalho e ao desenvolvimento científico e tecnológico e, assim, à competitividade. Porém, a cidadania não é totalmente esquecida. É o que se pode observar entre as suas diretrizes curriculares, em que se destacam a educação tecnológica básica, a compreensão do significado da ciência, das letras e das artes, o processo histórico de transformação da sociedade e da cultura, a língua portuguesa como instrumento de comunicação, acesso ao conhecimento e o exercício da cidadania.

Quanto à educação profissional, constituem avanços significativos o fato de que, pela primeira vez, o tema aparece integrado à legislação educacional, com a possibilidade de acesso de alunos matriculados ou egressos de vários níveis de ensino e dos trabalhadores em geral ou também a possibilidade de certificação de conhecimento adquirido no mundo do trabalho para prosseguimento ou conclusão dos estudos (arts. 39, 41 e 42).

A educação profissional pode se efetuar em três níveis: básico, destinado à qualificação, requalificação e reprofissionalização de trabalhadores, independente de qualidade; técnico, destinado a proporcionar habilitação profissional a alunos matriculados ou egressos do ensino médio; e tecnológico, correspondente a cursos de nível superior na área tecnológica, voltados para egressos dos ensinos médio e técnico.

A educação profissional de nível técnico é aquela seqüencial ou concomitante ao nível médio, mas os currículos dos ensinos médio e técnico são desvinculados. A separação entre a formação geral e a específica tem sido criticada no sentido da importância da integração da base específica da atividade produtiva à base comum e geral do conhecimento. Porém, o Conselho Nacional de Educação, através do Parecer 17/97, mostrou que a educação profissional de qualquer nível não substitui a educação básica, mas sim a complementa. Se a opção do aluno for pela profissionalização no nível médio, poderá “cursar paralelamente escolas técnicas" (Lobo, 1998).

A afirmação a seguir mostrará criticamente a base produtiva da reforma do ensino médio, ou seja, a idéia de educação para a competitividade: "Nessa conjuntura (...) encontramos o campo onde podemos questionar as concepções e políticas de educação básica, formação técnico-profissional e processo de qualificação, requalificação e reconversão, que vêm à pauta no Brasil dos anos 90 vincadas, fortemente, por uma perspectiva produtivista. (...) Voltou-se a afirmar, então, que a inserção dos países do bloco periférico ao processo de globalização em curso somente será possível através do ajuste de seu sistema educacional, sob a nova base científica e tecnológica. Tal (des)ajuste tem suas bases políticas na educação e formação técnico-profissional para o desenvolvimento das habilidades básicas, de atitudes e valores, competências para a gestão de qualidade, para a competitividade e produtividade e, conseqüentemente, para a 'empregabilidade'. Esta seria, uma vez mais, a exemplo do que foi a Teoria do Capital Humano na sua época, a 'chave de ouro' para desvendar o enigma do subdesenvolvimento e da exclusão" (Ignácio, 1999:97).

Dessa forma, pode-se perceber que a política educacional para o ensino fundamental tem sido pensada prioritariamente na sua dimensão social, ou seja, para a cidadania social, embora também possa ser considerada para o desenvolvimento científico e tecnológico e para o aumento da competitividade. Já o ensino médio tem sido considerado prioritariamente na sua dimensão econômica, ou seja, para a promoção do desenvolvimento tecnológico e da competitividade, seja do indivíduo através do aumento da sua empregabilidade, seja do país ou das empresas que incorporem inovações tecnológicas. No entanto, a dimensão social não pode ser esquecida, pois a cidadania só será de fato fortalecida à medida que a educação básica, e não somente a educação fundamental, seja universalizada.

Essas idéias sobre educação (competitividade e cidadania) vinculam-se, por um lado, ao contexto de globalização que inclui o Brasil na esfera da competição internacional e, por outro, ao contexto de democratização que avançou muito em termos de processo político, mas que deve avançar mais no que se refere à justiça social. 


\section{CONCEPÇÕES DE EDUCAÇÃO NAS POLÍTICAS DO ENSINO SUPERIOR E DA PESQUISA CIENTÍFICA E TECNOLÓGICA}

E o ensino superior, como está sendo pensado na década de 90 ?

As políticas para o ensino superior têm se orientado por alguns temas: a sua diversificação; a redefinição da sua autonomia; e a avaliação de seu desempenho. A proposta de diversificação do ensino superior está baseada no questionamento do modelo único de universidade implantado em 1968 (Martins, 1998). A partir de então, esse ensino seria oferecido por universidades públicas e gratuitas que deveriam associar ensino e pesquisa. A política atual propõe a saída do modelo único, possibilitando que a universidade ofereça formação científica (associando ensino e pesquisa), mas que também instituições de ensino superior possam oferecer formação profissional, tecnológica e formação de professores. Porém, essa saída só teria condições de se efetivar com a autonomia universitária. A definição da autonomia se enquadra na intenção de diminuir os controles burocráticos e normativos, garantir liberdade de organização dos serviços e execução de tarefas, estabelecendo um controle baseado na avaliação do desempenho. Essa avaliação se aplica ao setor público, influindo na distribuição de recursos, e ao setor privado, implicando o processo de credenciamento e recredenciamento de recursos.

São os objetivos, metas e prioridades definidos pelas instituições, a partir de certos critérios, que vão balizar a avaliação. É o estabelecimento desses objetivos, que não precisam ser os mesmos para todas as instituições de ensino superior, que favorecerá a diversificação do sistema. Dessa forma, percebe-se a associação feita entre os três eixos da política para o ensino superior.

Além dessas questões que constituem hoje a agenda da discussão sobre o ensino superior e que não serão aqui objeto de análise, também circula a idéia de que a universidade, juntamente com outras instituições como as empresas, o governo e as organizações não-governamentais, estaria tendendo, nas suas atividades de pesquisa, a desenvolver um novo modo de produção do conhecimento, dentro da concepção de educação para a competitividade.

Dessa forma, as análises recentes sobre a universidade inclinam-se para contextualizá-la dentro de uma "economia do saber", no sentido de vincular a produção e a transmissão do conhecimento às necessidades do mercado.
Gibbons, analisando sobretudo os países desenvolvidos, aponta o aumento da necessidade de conhecimento científico e tecnológico pela indústria na sociedade contemporânea. $\mathrm{O}$ conhecimento especializado torna-se um fator-chave na determinação das vantagens comparativas entre as empresas. Em decorrência da grande competitividade internacional, muitas empresas querem introduzir novas tecnologias e, por isso, requerem conhecimento especializado. As empresas então se envolvem em arranjos cooperativos com a participação das universidades, do governo e de outras empresas (Gibbons, 1994). Daí a importância da educação.

Ou seja, a busca de competitividade no processo de globalização é uma das condições de emergência do novo modo de produção do conhecimento, que implica transformações na educação em geral e, sobretudo, no ensino superior. Esse novo modo de produção do conhecimento situa-se num contexto de aplicação, no sentido que desenvolve pesquisas a partir da necessidade de resolver problemas práticos ou de atender demandas econômicas ou sociais e não apenas de interesses cognitivos, como na pesquisa básica. Caracteriza-se pela transdisciplinariedade, pois se o conhecimento é produzido num contexto de aplicação e não apenas com a intenção de acumulação do conhecimento na área, muitas vezes o problema a ser solucionado através do conhecimento exige que disciplinas complementares trabalhem a seu respeito. Também o novo modo de produção do conhecimento pressupõe uma heterogeneidade institucional, no sentido que ele não é desenvolvido apenas na universidade, envolvendo várias organizações, incluindo empresas multinacionais, empresas de redes, empresas pequenas de alta tecnologia, universidades, laboratórios de pesquisa, ONGs, como também envolve programas nacionais e internacionais de pesquisa.

Além disso, o conhecimento produzido não é orientado apenas para os pares (os membros da comunidade científica), mas também para os não-produtores de conhecimento, implicando uma maior responsabilidade social do conhecimento. Nos anos mais recentes, houve um aumento da consciência pública sobre meio ambiente, saúde, reprodução, etc., que estimulou a produção do conhecimento já dentro desses novos moldes. Certos movimentos sociais e ONGs nessas áreas procuram influenciar nas decisões sobre as pesquisas científicas e tecnológicas, o que revela também uma maior democratização.

O novo modo de produção de conhecimento provoca mudanças no ensino superior, pois a pesquisa desenvolvida tradicionalmente nas universidades era mais disci- 
plinar e se realizava sobretudo num contexto acadêmico orientado por interesses da comunidade científica e do processo de conhecimento e não por sua utilidade econômica ou social. No entanto, a consolidação do novo modo de produção de conhecimento não implica, necessariamente, a substituição do antigo. Eles podem se desenvolver simultaneamente, dando margem à realização de pesquisas básicas, ao mesmo tempo em que são estimuladas pesquisas aplicadas e desenvolvimento de tecnologias, só que esses processos cada vez mais não se realizam separadamente.

Assim, a lógica da diversificação do ensino superior vincula-se à idéia de diversificação da pesquisa universitária, sem que isso signifique, necessariamente, uma desvalorização da universidade - pelo fato de ela estar associada a outras instituições -, nem uma redução da pesquisa acadêmica - pelo fato de ela não ser a única desenvolvida no contexto universitário. ${ }^{3}$

Se, por um lado, é a busca da competitividade no mundo atual que leva à maior procura do conhecimento e da educação pela sociedade, por outro, é também a democratização da sociedade que demanda uma maior responsabilidade social do conhecimento. Segundo Gibbons (1994), a massificação do ensino superior também viabiliza a emergência do novo modo de produção de conhecimento, pois o número de pessoas com competência em pesquisa cresce demais para ser absorvido apenas nas universidades. Os lugares com competência em pesquisa diversificam-se. Além disso, o desenvolvimento das tecnologias de comunicação e informação permite a interação entre diferentes instituições (universidades, governo, empresas, ONGs) e diferentes países, possibilitando a realização de pesquisas em rede. Esses são os novos rumos do conhecimento que refletem mudanças ocorridas no sistema de ensino superior.

Dessa forma, Gibbons aponta a heterogeneidade institucional como uma característica importante da produção científica e tecnológica contemporânea, supondo que essa produção se faça agora em vários lugares, como laboratórios governamentais e as empresas privadas, além das universidades. Por outro lado, Leydesdorff e Etzkowitz (1996) sublinham a importância do papel da universidade na "tripla hélice" e sugerem estudar a dinâmica das relações entre a universidade, o governo e a indústria. Já Knorr-Cetina trabalha com o conceito de "arenas transepistêmicas", considerando, no processo de produção do conhecimento, as decisões negociadas dos pesquisadores e de outros atores não científicos, mas que também participam do processo muitas vezes com interesses nos resultados das pesquisas (empresários, governo, ONGs). Em qualquer uma destas abordagens, o importante é destacar que a produção do conhecimento se faz, nessa nova tendência, a partir de vários atores sociais e de várias instituições relacionadas entre si.

Ou seja, estão emergindo transformações no modo de produção do conhecimento, que se vinculam à mundialização da economia, à ascensão da economia dos saberes ou da informação e à introdução das mudanças tecnológicas no processo de produção. Essas mudanças, aliadas à reformulação do papel do Estado que diminui os recursos públicos consagrados à educação, sugerem uma racionalidade econômica que se faz sentir na pesquisa universitária, com a passagem de uma política da ciência para uma política da inovação (Doray e Pelletier, 1999).

Porém, há também o fenômeno da democratização que aumenta a necessidade de "social accountability" do conhecimento, ou seja, de uma maior participação da sociedade no processo de conhecimento. A consolidação democrática pode levar os pesquisadores a trabalharem considerando demandas socioeconômicas, pois a opinião pública tende a cobrar mais resultados da pesquisa científica e tecnológica. Isso faz com que aumente o peso das pesquisas temáticas e determine as agendas de pesquisa em função de demandas externas.

Em trabalho realizado em 1994 (Sobral e Trigueiro, 1994), mostrou-se que o Brasil já possuía capacitação tecnológica em determinadas áreas, mas que apenas em parte ocorria desenvolvimento das chamadas tecnologias de ponta ou atendimento de demandas econômicas e sociais fundamentais para o país. Afirmou-se, então, que muitas das limitações do nosso desenvolvimento científico e tecnológico centravam-se na questão da formação de recursos humanos, que, por sua vez, ligava-se a deficiências do nosso sistema educacional.

Por outro lado, o modelo de desenvolvimento científico e tecnológico, impulsionado pela ciência e que seguia sobretudo a lógica do processo de conhecimento e não as necessidades econômicas e sociais, adotado predominantemente no Brasil, havia se mostrado eficiente no sentido de constituir uma comunidade científica competitiva. Porém, precisaria ser combinado a outros procedimentos que envolveriam, além das demandas do mercado acadêmico-científico, outras demandas do mercado econômico e social.

Por essa razão, propôs-se, nessa ocasião, o estabelecimento de um modelo misto de desenvolvimento científicotecnológico, que envolveria a combinação de dois tipos de procedimento: o desenvolvimento científico e tecnológico, 
impulsionado pela ciência; e aquele orientado pela demanda econômico-social ou pelo mercado. Se o modelo de “impulsão pela ciência”, por um lado, estava sendo satisfatório no que se refere à qualidade dos pesquisadores, das equipes e dos projetos de pesquisa, por outro, estava sendo insuficiente quanto à valorização ou à escolha de temas dentro de certas áreas. Com o modelo misto, ocorreria então a união do mercado econômico-social ao mercado acadêmico.

Sendo assim, os eixos orientadores da pesquisa universitária na atualidade a associam à economia e à intervenção social, ou seja, refletem as idéias de educação para a competitividade e educação para a cidadania social, embora com um maior reforço para a questão propriamente econômica.

A título de conclusão, pode-se enfatizar a idéia inicial de que a concepção de educação muda através dos tempos e que a sociedade contemporânea, considerada sociedade do conhecimento, requer um repensar sobre a educação. Na década de 90, ela está sendo pensada como educação para competitividade (mais no nível médio e superior) e como educação para a cidadania social (mais no nível fundamental).

Porém, é importante destacar que uma única concepção de educação não pode dominar inteiramente, da mesma forma como se afirmou anteriormente que o novo modo de produção de conhecimento não pode excluir o antigo ou que se sugeriu um modelo misto de desenvolvimento científico e tecnológico.

No que se refere à educação, as dimensões social e econômica não são necessariamente excludentes. A visão utilitarista não pode eliminar a visão humanista.

\section{NOTAS}

E-mail da autora: fernanda@unb.br

1. Algumas das idéias desenvolvidas nesse tópico encontram-se em Sobral (1980 e 1993).

2. A interdisciplinariedade é a forma que se tem utilizado nas novas áreas do conhecimento para não só atender aos rumos recentes dos estudos, pesquisas e desenvolvimentos técnicos, mas também para testar e descobrir pistas mais promissoras de conquistas e avanços técnico-científicos. A intercambialidade é a forma atualmente mais vantajosa de dinamizar o conhecimento pelo aproveitamento de teorias, metodologias e técnicas de pesquisa de uma disciplina em outra, ou de uma área do conhecimento em outra. A experimentação não é algo estritamente novo, mas tem estado muito mais presente, mesmo na elaboração e teste de teorias científicas, graças ao auxílio extraordinário da ciência da computação.

3. Estudos recentes sobre as universidades canadenses mostram que não há oposição entre, de um lado, os pesquisadores que desenvolvem pesquisa estritamente aplicada ou em colaboração e, de outro, aqueles que fazem pesquisa fundamental (Godin, 1998). Como as leis de concentração das atividades de pesquisa deixam antever, são geralmente os mesmos pesquisadores que se engajam nos dois tipos de atividades. Além disso, os pesquisadores que investem na pesquisa em colaboração encontram algumas vantagens, como o acesso aos novos temas de pesquisa, a dados não publicados e a fontes adicionais de financiamento (Meyer- Kramer e Schnoch, 1998; Bataini, Martineau et Trépanier, 1997).

\section{REFERÊNCIAS BIBLIOGRÁFICAS}

BATAINI, S.; MARTINEAU, Y. e TRÉPANIER, M. Le secteur biopharmaceutique québécois et les investissemets directs étrangers: dynamique et impacts des activités de $R$-D. Étude réalisée pour le Conseil de la science et de la technologie du Québec, 1997.

BENAKOUCHE, R. "A autonomia universitária no contexto da reforma do aparelho do Estado". Universidade e Sociedade, v.9, n.19, maio/agosto 1999.

CHINOY, E. "Socialy mobillity trends in USA". American Sociological Review, n.20, 1955.

DORAY, P. e PELLETIER, P. Les politiques publiques et l'université: quelques points repères historiques (1960-1998), 1999, mimeo.

DURKHEIM, E. Educação e Sociologia. São Paulo, Edições Melhoramentos, 1975.

FERNANDES, F. Capitalismo dependente e classes sociais na América Latina. Rio de Janeiro, Zahar, 1972.

GIBBONS, M. et alii. The new production of knowledge. Londres, Sage, 1994. GLASS, D.V. Social mobility in Britain. London, Routledge Kegan Paul, 1954.

GODIN, B. Besides Academics Publications: wich sector compete, or are they competitors. Scientometrics, v.33, 1998, p.3-12.

GODIN, B. e GINGRAS, Y. "L'impact de la recherche en collaborátion et le rôle des universités dans le système de productions des connaissances". Interuniversitaire de Recherche sur la Science et la Tecnologie, n.7, 1999.

IBGE. Programa Nacional de Amostragem Domiciliar. Rio de Janeiro, 1996.

IGNÁCIO, P.C. de S. "Educação e ensino técnico". Universidade e Sociedade, v.9, n.19, maio/agosto 1999.

LEVY, S. Toward an economic analysis of the brazilian university. Brasília, CNRH/Ipea, 1972, mimeo.

LEYDESDORFF, L. e ETZKOWITZ, H. "Emergence of a triple-helix of university-industry-government relations". Science and public policy, n.27, 1996, p.835-851.

LOBO, H.H. de. O ensino médio no Brasil-diagnóstico e perspectivas. 1998, mimeo.

MARSHALL, T.H. Class, citizenships and social development. Connectut, Greenwood Press, 1979.

MARTINS, C.B. Notas sobre o ensino superior brasileiro. Brasília, 1998, mimeo. MEC. Balanço do primeiro ano do Fundef. Brasília, mar. 1999.

MELLO, G.N. Cidadania e competitividade. São Paulo, Cortez Editora, 1998.

MEYER-KRAMER, F. e SCHMOCH, V. "Science-Based Technologies: University-Industry Interations in Four Fields." Research Policy, 27:835851,1998 .

PELIANO, J.C.P. A importância da educação para o novo modo de produção do conhecimento, 1998, mimeo.

SAVIANI, D. Escola e democracia. São Paulo, Cortez, 1985.

SCHULTZ, T. O capital humano. Rio de Janeiro, Zahar, 1973.

SOBRAL, F.A. da F. Educação e mudança social: uma tentativa de crítica. São Paulo, Cortez, 1980.

"Universidade e pesquisa na nova Constituição". Em Aberto. Brasília, ano 8, n.43, jul./set. 1989.

"Educação, universidade e sociedade". Natureza, história e cultura. Porto Alegre, UFRGS/SBS, 1993.

. "Educação, ciência e tecnologia no Brasil na década de 90". Anuário da Educação. Rio de Janeiro, Tempo Brasileiro/Unigranrio, 1996.

SOBRAL, F.A. da F. e TRIGUEIRO, M. "Limites e potencialidades da base técnico-científica". In: SOBRAL, F.A. e FERNANDES, A.M. (orgs.). Colapso da ciência e tecnologia no Brasil. Rio de Janeiro, Relume Dumará, 1994.

TEIXEIRA, Z.A. "Políticas públicas e educação para crianças, adolescentes e jovens”. Políticas públicas sociais. Brasília, Inesc, 1999. 